Western University

Scholarship@Western

Aboriginal Policy Research Consortium International (APRCi)

9-15-2012

\title{
Kerin O'Dea: improving the health of Indigenous Australians
}

Tony Kirby

Follow this and additional works at: https://ir.lib.uwo.ca/aprci

Part of the Other Public Health Commons

Citation of this paper:

Kirby, Tony, "Kerin O’Dea: improving the health of Indigenous Australians" (2012). Aboriginal Policy Research Consortium International (APRCi). 238.

https://ir.lib.uwo.ca/aprci/238 


\section{Profile}

\section{Kerin O'Dea: improving the health of Indigenous Australians}

Kerin O'Dea's language teacher mother gave her the belief that with hard work she could do well in whatever profession she chose. With a slew of senior research appointments behind her, most recently as Director of the Sansom Institute for Health Research at the University of South Australia, O'Dea has certainly proven her mother right. A professor of Nutrition and Public Health in the Health Sciences Division of the University of South Australia, she has spent many years researching diet and chronic disease in Indigenous Australians. "Kerin O'Dea has dedicated her whole career to the Australian Indigenous health area and is a legend for her activities on these issues", says Paul Zimmet, Director of International Research at Melbourne's Baker IDI Heart and Diabetes Institute.

But it was the mechanics of how drugs worked and were developed that initially fascinated O'Dea. Her postgraduate years alternated between pharmacology and physical biochemistry, and, like many young Australian researchers, she linked her career development with opportunities to travel, working for Bayer in Germany, INSERM in Paris, and the Cleveland Clinic in the USA. During this time, she studied alpha glucosidase inhibitors, the glycaemic index, and the feeding patterns of rats, discovering that giving them food twice during a day-night cycle made them gorge on food rather than nibble it as they do in nature. This unnatural feeding pattern caused abnormal metabolism, which was to become the basis of much of O'Dea's future work.

It was in the late 1970s, after returning to Australia, that O'Dea began using her research in nutrition to help understand the health of Australia's Indigenous people. She took a post at Melbourne's Royal Children's Hospital, working with an early mentor Donald Cheek. "While his focus was on malnutrition in children, we saw that many Indigenous people were developing diabetes", recalls O'Dea. To find out why, she led a series of studies in remote locations to study eating and lifestyle behaviours among Indigenous Australians. One study involved getting a group of largely diabetic or pre-diabetic Indigenous Australians to adopt a so-called hunter-gatherer lifestyle. "Three foods were contributing $80 \%$ or more of the diet: kangaroo, freshwater fish, and yams", O'Dea explains. The study participants had much improved blood glucose control, including reversal of diabetes in some individuals. "The combination of calorie restriction-inadvertent, but part and parcel of being a hunter-gatherer-causing weight loss, plus the healthier diet and increased physical activity all contributed to their improved metabolic profiles. In western populations today, we don't have to do the physical activity and yet we still get the 'reward' of a diet rich in fat, salt, and sugar", O'Dea told The Lancet.
The links between nutrition, chronic disease, and the health of Indigenous Australians has remained a focus of O'Dea's research and she is currently leading a multimillion dollar National Health and Medical Research Council (NHMRC) Program Grant on "Improving chronic disease outcomes for Indigenous Australians: causes, interventions, system change". According to Berit Lilienthal Heitmann, of the Institute of Preventive Medicine, Copenhagen, Denmark, "Kerin is one among few who is greatly respected for her research and efforts by Indigenous societies. She generously shares her knowledge and wisdom—something that many PhD students, colleagues, and friends have greatly benefited from for more than 30 years."

O'Dea's research has also extended into the Mediterranean diet. She points to immigrant Mediterranean populations in Australia, such as Greeks and Italians, who while having similar or higher rates of obesity than Anglo-Celtic Australians, actually seem to live longer. O'Dea suggests dietary composition might be a key factor in this, and together with colleagues is working on the Melbourne Collaborative Cohort Study which is looking at this issue. "A truly healthy lifestyle needs to take account of combinations of different foods, and how they are cooked. Unsaturated fats seem to be less likely to promote weight gain than saturated fat", O'Dea says. Her expertise in this area was one reason for her appointment as inaugural chair of the NHMRC's Prevention and Community Health Committee. O'Dea has also led projects on diet and lifestyle to prevent vascular diseases and diabetes in susceptible remote populations, working with both Indigenous and non-Indigenous people.

To prevent obesity and diabetes, $\mathrm{O}^{\prime}$ Dea thinks a population approach similar to that adopted with tobacco is the way ahead. "We desperately need data on how such approaches will work for obesity and diabetes. Many people are keeping a close eye on Denmark's fat tax experiment", she says. Making healthier foods available for those who can least afford them is also important, she argues: "We subsidise diesel fuel in rural Australia, so why not healthy food?" To this end, she serves as a director for Outback Stores, an organisation committed to providing healthy and affordable foods in remote Australian communities. Having contributed to the explosion in nutrition-related research in the past few decades, O'Dea says it's now time for concerted action. "One of the things that characterises much public health research is that we describe how bad things are but don't do enough intervention," she says. "Today, taking no action can be more expensive than the interventions themselves."

Tony Kirby

tony@tonykirby.com

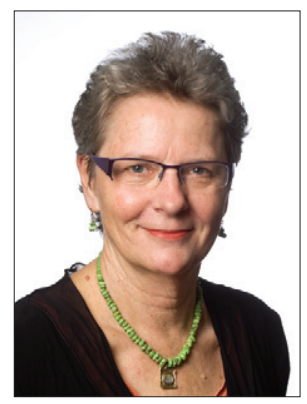

